\title{
Political Orientations of Chinese Metropolitan Residents: A Survey of Beijing, Shanghai, and Guangzhou Residents*
}

Jo0, Jang-H wan

(H anshin University)

$\langle$ CONTENTS $\rangle$

I. Introduction

II. Survey and Data

III. Relationship between

Demographics, Political Trust, and

Political Efficacy

\section{Type of Political Orientation} According to Region

V. Conclusion

- Keywords : political orientation, political trust, political efficacy, China

\section{【ABSTRACT】}

To determine whether political characteristics vary by region in China, I surveyed 500 people in the Beijing, Shanghai, and Guangzhou regions in June 2005. Of the demographic variables studied (i.e., education, age, gender, and income), only education was statistically related to type of political orientation. However, the relationship between regional variables and political orientation was valid. Beijing, Shanghai, and Guangzhou residents varied in political trust, political efficacy, and subgroups of political orientation. This shows that political characteristics vary by region in China. Moreover, I was able to identify the characteristics of political orientation in each region.

\footnotetext{
*This work was supported by Hanshin University Research Grant.
} 


\section{Introduction}

Socialist China has seen little systematic empirical research regarding political issues (e.g., political culture, attitudes, behavior). However, much research has been conducted on political elites, official political policies, and political processes. ${ }^{1)}$ It used to be that for individuals and foreign institutions to conduct social surveys the Chinese government had to inspect and approve the survey. But in October 2004, the government passed the Procedure for Outside Investigations Management, ${ }^{2)}$ which allows foreign agents or individuals to conduct surveys with the collaboration of Chinese agencies or agent companies that have received approval from the Chinese Statistical Department Bureau. As of October 2006, 260 local research institutions and firms had obtained this official approval via the Permit for Outside Investigation. Of these permits, 234 expired on September 25, 2007, and 26 expired on September 25, 2008. ${ }^{3)}$ Although this is good news for those outside of China who want to conduct social surveys, restrictions still exist on certain issues related to surveying.

In spite of these restrictions, there have been efforts to use surveys to conduct research on political issues. ${ }^{5}$ Research on political orientation and culture is one such

1) Alan P. L. Liu, Mass Politics in the People's Republic: State and Society in Contemporary China (Boulder, Colo.: Westview Press, 1996), p. 2.

2) State Statistical Bureau, Politics and Law Division, 2004, "Shewai diaocha guanli banfa" (State Statistical Bureau press interview), http://www.stats.gov.cn/tjgl/sxdcglgg/zywj/t20041118_402209070.htm.

3) State Statistical Bureau, Politics and Law Division, 2004, "Qude shewai diaocha xukezheng jigou mingdan (di yi pi)" (The list of agencies to obtain 'A Permit for Outside Investigation' [1]), http://www.stats.gov.cn/tjgl/swdeglgg/spgg/t20041118_402209054.htm;State Statistical Bureau, Politics and Law Division, 2005, "Qude shewai diaocha xukezheng jigou mingdan (di er pi)" (The list of agencies to obtain 'A Permit for Outside Investigation' [2]), http://www.stats.gov.cn/tjgl/swdcglgg/spgg/t20050414_402242828.htm; State Statistical Bureau, Politics and Law Division, 2005, "Qude shewai diaocha xukezheng jigou mingdan (di san pi)" (The list of agencies to obtain 'A Permit for Outside Investigation' [3]), http://www.stats.gov.cn/tjgl/swdcglgg/spgg/t20050414_402264266.htm.

4) The Procedure for Outside Investigations Management bans social surveys that (a) are against the basic tenets of the Chinese Constitution; (b) may have an undesirable effect on national unity, sovereignty, or territorial integrity; (c) may disturb social order or have a detrimental effect on social stability; or (d) may impair the legal rights of other citizens. State Statistical Bureau of People's Republic of China, 2004, "Shewai diaocha guanli banfa" (Procedure for outside investigations management), p. 2.

5) Important recent research efforts include the following: Melanie Manion, "The Electoral Connection in the Chinese Countryside," American Political Science Review 90-4 (December 1996), pp. 736-48; Kent Jennings, "Political Participation in the Chinese Countryside," American Political Science Review 91-2 (December 1997), pp. 361-72; Tianjian Shi, Political Participation in Beijing (Cambridge, MA: Harvard University Press, 1997); Daniel V. Dowd, Allen Carlson and Mingming Shen, "The Prospects for Democratization in China: Evidence 
effort. An interesting fact is that the same research on these topics from different time periods produces different results. Research on political orientation conducted in the early 1990s asserted that the Chinese retained traditional "anti-democratic" notions such as authoritarianism, passivism, awe of politics, and patience. ${ }^{6}$ Based on a 1995 survey, Chen, Yang, and Hillard found that Beijing residents strongly supported the government and that their values were similar to those revealed in a 1990 survey. ${ }^{7}$ In addition, other researches on Beijing residents have been conducted based upon diachronic surveys. Shi claimed that both the frequency and the intensity of Beijing residents' political activism increased during the eight-year period between 1988 and 1996. ${ }^{8}$ Chen conducted random sample surveys in the urban part of Beijing in 1995, 1997, and 1999, and made the discovery that the Chinese Communist regime commands high levels of political legitimacy. ${ }^{9}$

In contrast, Yanlai Wang conducted a social survey in 2000 in Shanghai municipal city, Jiangsu province, and Zhejiang province using the same survey items that Nathan and Shi had used in 1990. Wang reported that residents in these areas were relatively more liberal and possessed more pro-democratic values since the "Open Door Policy." ${ }^{10)}$ Although these works produced different outcomes, they all show that the political orientations of the Chinese have changed with the times. In this sense, it is meaningful to identify the political orientation of the residents in different areas during the same period.

from the 1995 Beijing Area Study," Journal of Contemporary China 8-22 (November 1999), pp. 365-80; Chepo Chan, "The Political Pragmatism of Chinese University Students: 10 Years after the 1989 Movement," Journal of Contemporary China 8-22 (November 1999), pp. 381403; Tianjian Shi, "Mass Political Behavior in Beijing," in Merle Goldman and Roderick MacFarquhar (eds.), The Paradox of China's Post-Mao Reforms (Cambridge, London: Harvard University Press, 1999), pp. 145-72; Kunan Hsin-Chi and Lau Siu-Kai, "Traditional Orientation and Political Participation in Three Chinese Societies," Journal of Contemporary China 11-31 (May 2002), pp. 297-318; Jie Chen, Popular Political Support in Urban China (Stanford: Stanford University Press, 2004); Jie Chen, "Sociopolitical Attitudes of the Masses and Leaders in the Chinese Village: Attitude Congruence and Constraint," Journal of Contemporary China 14-44 (August 2005), pp. 445-64.

6) Andrew J. Nathan and Tianjian Shi, "Cultural Requisites for Democracy in China: Finding from a Survey," Daedalus 122 (Spring 1992), pp. 95-123; Andrew J. Nathan and Tianjian Shi, "Left and Right with Chinese Characteristics, Issues and Alignments in Deng Xiaoping's China," World Politics 48-4 (July 1996), pp. 522-50.

7) Jie Chen, Zhong Yang and Jan William Hillard, "The Level and Sources of Popular Support for China's Current Political Regime," Communist and Post Communist Studies 30-1 (March 1997), pp. 45-64.

8) Shi (1999).

9) Chen (2004).

10) Yanlai Wang, Nicholas Rees and Bernadette Anreosso-O'Callaghan, "Economic Change and Political Development in China: Finding from a Public Opinion Survey," Journal of Contemporary China 13-39 (May 2004), pp. 221-22. 
The present article is based on an empirical survey conducted with 500 residents from Beijing, Shanghai, and Guangzhou in 2005. The survey was designed to closely examine regional identity, but not attitudes toward democracy. The goal of this study is to investigate Chinese regional identity from a political perspective by studying characteristics of each region.

The idea of regional identity has been implicit in geography for a long time. Regional identity refers to those features of nature, culture, and people that are used in the discourses and classifications of science, politics, cultural activism, regional marketing, governance, and political or religious regionalization to distinguish one region from another. ${ }^{11)}$ It is a key element in making a region a social/political space. ${ }^{12)}$

One can assume that the political characteristics of regional residents differ from those found in previous research. To begin with, an academic trend divides China according to regional characteristics. This trend was systemized by G. W. Skinner, who divided the Chinese Empire into nine macro regions according to variables such as natural conditions and market structures. ${ }^{13)}$ Child and Stewart used labor market characteristics to confirm assertions of distinct cultural differences among the regions. ${ }^{14)}$

Although they did not use statistical methods, some research efforts have asserted that there are regional differences or regional identities on China's political landscape. Hendrischke and others have observed that each area (primarily province) searches for its identity through development, improvement of autonomous attitude, and reformation/ liberalization. These researchers have explained this through analyses of individual provinces. ${ }^{15}$

Chung argued that the effects of decentralization have differed by region. Chung classified regions by type: pioneering, bandwagoning, and resisting. By separating causes into endogenous and exogenous variables, he eminently considered endogenous variables (i.e., each region's discriminatory conditions) as well as exogenous ones (e.g., those that signified the political relationship with the central government). ${ }^{16)}$

Liu also studied provincial identity, pointing out those distinct identities and political

11) Anssi Paasi, "Region and Place: Regional Identity in Question," Progress in Human Geography 27-4 (August 2003), p. 478.

12) Michael Keating, "Rethinking the Region: Culture, Institutions and Economic Development in Catalonia and Galicia," European Urban and Regional Studies 8-3 (July 2001), pp. 217-34.

13) G. W. Skinner, The City in Late Imperial China (Stanford, Calif.: Stanford University, 1977), pp. $9-17$.

14) John Child and Sally Stewart, "Regional Differences in China and Their Implications for Sino-Foreign Joint Ventures," Journal of General Management 23-2 (Winter 1997), pp. 65-86.

15) Hans Hendrischke and Feng Chongyi, The Political Economy of China's Provinces (London: Routledge, 1999).

16) Jae Ho Chung, Central Control and Local Discretion in China (Oxford: Oxford University Press, 2000), pp. 6-10. 
cultures among Chinese provinces are more discernable today than ever. He argued that provinces whose identities and political cultures have become explicit tend to form five clusters reflecting common cultures and/or politics or strategies: (a) modernist: Jiangsu, Shanghai, Zhejiang, Fujian, Guangdong; (b) traditionalist: Shanxi, Hebei, Henan, Liaoning, Jilin, Heilongjiang; (c) transitional: Sichuan, Hunan, Jiangxi; (d) parochial: Gansu, Shaanxi, Guizhou, Guangxi; and (e) separatist (the major minority nationalities). ${ }^{17)}$

Finally, even previous research on Chinese citizens' understandings of democratization has revealed the possibility of regional differences. Similarities and differences in the surveys conducted in Beijing in 1990 and in Jiangsu, Zhejiang, and Shanghai in 1995 may have resulted from either the passage of time or regional differences. Would researchers have seen similar results if the surveys had been conducted in Jiangsu, Zhejiang, and Shanghai in 1990 and in Beijing in 1995? This is certainly a matter worth studying.

The present research examined empirically the commonly accepted (but not proven) proposition that, with regard to politics, China's residents have their own diverse characteristics. That is, this research attempted to verify the hypothesis that China might not have just one political characteristic that corresponds to residence. The result of this research shows us the political variation of socialist China which sticks to the party-state regime in the regional and synchronic aspects. This also shows the difference from previous research which mainly focuses on particular area or diachronic approaches. Although this research covers three areas, the specific political orientation of these areas can be characterized. This is significant in a sense that this research through the extension of the cases could be the first step for the further study on the Chinese regional identity. Lastly, this research verifies the existence of the regional identity statistically, which complements the limitation of previous qualitative researches. with qualitative approach.

I aim to clarify Jeffery M. Paige's concept of political orientation to determine whether there are differences in the political perspectives of each resident. According to Paige, political orientation is a citizen's attitude toward politics and consists of two elements: political efficacy and political trust. Political efficacy includes the subsidiary factors of reactivity and simplicity toward a political system. Political trust includes subsidiary aspects of reliability, legality, and capability toward a political structure. Combining these two elements (fluctuations in political efficacy and political trust) results in four

17) Alan P. L. Liu, "Provincial Identities and Political Cultures: Modernism, Traditionalism, Parochialism, and Separatism," in Shiping Hua (eds.), Chinese Political Culture 1989-2000 (Armonk, NY: Sharpe, 2001), pp. 247-75. 
political orientations: allegiant, dissident, subordinate, and alienated. The nature of each orientation's corresponding political system can be categorized using the same method (see Figure 1). ${ }^{18)}$

〈Figure 1〉 Relationship of Trust and Efficacy to Political Orientation and Nature of Political System

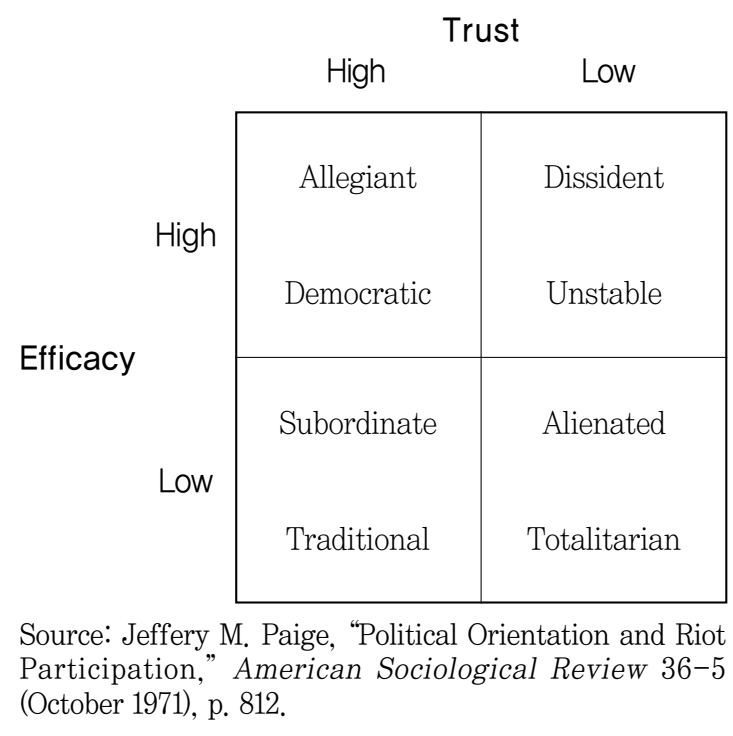

This study was based on the positive survey of political orientation conducted with the residents of Beijing, Shanghai, and Guangzhou. These are northern, eastern, and southern China's most well-known cities. In the next section I describe the survey used in this study. Then I examine preliminary findings (i.e., differences in political trust and political efficacy by demographic variables). Next I categorize the political orientations of the residents of the three metropolitan areas. I conclude with a summary and a discussion of the limitations and implications of the study.

\section{Survey and Data}

I measured three aspects of political trust: reliability, legality, and capability. This study defined reliability as the degree of trust that a resident shows toward a political system or organization. To measure this, I asked residents to respond to the following item: "We have a reliable government." Legality was defined as the degree of legitimacy

18) Jeffery M. Paige, "Political Orientation and Riot Participation," American Sociological Review 36-5 (October 1971), pp. 810-13. 
a political system or organization enjoys as assessed by a resident (measured by response to "We have a legal government"). Capability was defined as the degree of capability of a political system or organization as assessed by a resident (measured by response to "Our government has strong capability").

I measured two aspects of political efficacy: reactivity and simplicity. Reactivity was defined as the degree to which a resident believes he or she can influence a political system or organization (measured by response to "I can influence the government's decision making”). Simplicity was defined as the degree of understanding a resident has of the complexity of a political system or organization's policy decision-making process (measured by response to "The process for constitution and establishing policies are complicated in China"). All items used a 7 -point scale, where $1=$ completely disagree and $7=$ completely agree.

$\langle$ Table 1〉 Design of Data

\begin{tabular}{cccccc}
\hline & & & & & (person) \\
\hline \multirow{4}{*}{ AGE } & & Beijing & Shanghai & Guangzhøu & Total \\
& $18 \sim 29$ & 125 & 125 & 125 & 375 \\
& $30 \sim 39$ & 125 & 125 & 125 & 375 \\
& $40 \sim 49$ & 125 & 125 & 125 & 375 \\
\multirow{2}{*}{ GENDER } & $50 \sim 59$ & 125 & 125 & 125 & 375 \\
\hline Total & Male & 250 & 250 & 250 & 750 \\
& Female & 250 & 250 & 250 & 750 \\
\hline
\end{tabular}

*Method of Data Sampling = Quota Sampling

The survey was carried out from June 5 to June 25, 2005, with residents of Beijing, Shanghai, and Guangzhou. An authoritative survey firm in Beijing used the quota sampling method. ${ }^{19)}$ A total of 500 people from each city were selected to represent a balance of ages, genders, and nativities. More than 90 percent of those surveyed were native to that region: 96.6 percent from Beijing, 97 percent from Shanghai, and 91.8 percent from Guangzhou. ${ }^{20)}$ Four age groups were represented: 18 (age of adulthood in China) through 29, 30 through 39, 40 through 49, and 50 through 59 (each group

19) Because of the sensitivity surrounding the researching of political issues, I have chosen not to disclose the name of the firm. However, it is a renowned multinational enterprise and possesses the aforementioned Permit for Outside Investigation.

20) This is important, considering the study focuses on the political orientations of residents of each region. I denote here people who were born, educated, and currently reside in the respective regions. As can be seen, natives constituted the majority of the sample population. 
constituted 25 percent of the whole). The gender distribution was 50 percent each for men and women (see Table 1).

Furthermore, average monthly household income was classified into 10 categories from less than 1,000 yuan to more than 20,000 yuan (see Table 2). The category 3,000 to 3,999 yuan was the most popular for Beijing and Guangzhou, representing 21.2 percent and 24.6 percent of respondents, respectively. In Shanghai, the category 5,000 to 6,999 yuan was the most popular, representing 23.6 percent. ${ }^{21)}$ Mean (standard deviation) income scores were 5.02 (1.910), 4.97 (1.854), and 3.81 (1.922) for Beijing, Shanghai, and Guangzhou, respectively.

$\langle$ Table 2〉 Distribution by Income

\begin{tabular}{ccccc}
\hline (yuan) & Beijing & Shanghai & Guangzhøu & Total(\%) \\
\hline Under 1,000 & 3 & 1.2 & 8.4 & 4.2 \\
1,000-1,999 & 5.6 & 6.8 & 17 & 9.8 \\
2,000-2,999 & 14.6 & 15.2 & 23 & 17.6 \\
3,000-3,999 & 21.2 & 21.6 & 24.6 & 22.5 \\
4,000-4,999 & 10.8 & 12.8 & 9.4 & 11.0 \\
5,000-6,999 & 20.6 & 23.6 & 8.8 & 17.7 \\
7,000-9,999 & 16 & 10.6 & 4.2 & 10.3 \\
10,000-14,999 & 5.8 & 5 & 2 & 4.3 \\
15,000-19,999 & 1.2 & 1.2 & 0.2 & 0.9 \\
over 20,000 & 1.2 & 2 & 2.4 & 1.9 \\
\hline Total & 100 & 100 & 100 & 100 \\
\hline
\end{tabular}

With regard to education, which was classified into six categories, most respondents were high school graduates: The proportions were 37.2 percent, 50.6 percent, and 47.2 percent for Beijing, Shanghai, and Guangzhou, respectively (see Table 3). Mean (standard deviation) scores were 3.65 (0.911), 3.35 (0.833), and 3.20 (1.010) for Beijing, Shanghai, and Guangzhou, respectively. ${ }^{22)}$

21) Beijing Statistical Bureau, "2004nian Beijing guomin jingji he shehui fazhan tongji gongbao" (Beijing Economic and Social Development Statistics Bulletin, 2004).

http://www.stats.gov.cn/tjgb/ndtjgb/dfndtjgb/t20050228_402231969.htm; Guangzhou Statistical Bureau, Guangzhou tongji nianjian 2004 (Guangzhou Statistical Yearbook, 2004) (Beijing: China Statistical Press, 2004), p. 237;Shanghai Statistical Bureau, "2004nian shanghai guomin jingji he shehui fazhan gongbao" (Shanghai Economic and Social Development Statistics Bulletin, 2004), http://www.stats.gov.cn/tjgb/ndtjgb/dfndtjgb/t20050126_402226082.htm.

22) These figures reflect well the underlying education levels of the three cities: The number of university students per 10,000 citizens is 335, 307, and 261 for Beijing, Shanghai, and Guangzhou, respectively. See State Statistical Bureau, General Statistics Division of 
〈Table 3〉 Distribution by Education

\begin{tabular}{lcccc}
\hline & Beijing & Shanghai & Guangzhou & Total(\%) \\
\hline Primary School & 0.8 & 0.6 & 3.6 & 1.7 \\
Middle School & 7.4 & 11.2 & 17.8 & 12.1 \\
High School & 37.2 & 50.6 & 47.2 & 45.0 \\
College & 36.8 & 27.8 & 19.4 & 28.0 \\
University (undergraduate) & 16.6 & 9.6 & 10.8 & 12.3 \\
University (graduate) & 1.2 & 0.2 & 1.2 & 0.9 \\
\hline \multicolumn{1}{c}{ Total } & 100 & 100 & 100 & 100 \\
\hline
\end{tabular}

\section{Relationship between Demographics, Political Trust, and Political Efficacy}

This section examines the relationship among demographic variables (i.e., gender, education, age, and income), political trust, and political efficacy. In so doing, it is possible to understand the relationship between other demographic variables and political orientations aside from regional variables.

I first observed the correlation among the demographic variables, political trust, and political efficacy. When the correlations were not significant, I then examined whether trust and efficacy varied by subgroup for each of the demographic variables and, if so, how they varied. To do this, I used a t test for gender and analyses of variance for the other variables.

Table 4 shows the results of the correlation analysis of demographic variables, political trust, and political efficacy. Of the demographic variables studied, only education correlated with trust and efficacy. In the case of education, reliability (one of the items of political trust) showed a coefficient of .098 from the 95 percent trust rate. This means that there would be more trust in the government if education levels were higher. For legality (i.e., "We have a legal government"), there was a coefficient of .066 from the 90 percent trust rate. This means that the higher the education level, the more legal the government was assessed. There was no statistically significant correlation between education and the assessment of government capability (i.e., "Our government has strong capability"). Regarding political reactivity (i.e., "I can influence the government's decision making"), there was a coefficient of -.063 from the 90 percent trust rate. This

National Economy, Xinzhongguo wushiwunian tongji ziliao huipian 1949-2004 (China compendium of statistics 1949-2004) (Beijing: China Statistical Press, 2005), p. 121, 393, 733. 
indicates that although there was a correlation between education and reactivity, having a higher education level did not mean one felt that he or she had more influence on government policy decisions.

〈Table 4〉 The Results of the Analysis on the Correlation among Demographic Variables, Political Trust, and Efficacy

\begin{tabular}{cccccccc}
\hline & Mean & S.D. & 1 & 2 & 3 & 4 & 5 \\
\hline 1 & 5.00 & 1.262 & 1.000 & & & & \\
2 & 5.03 & 1.281 & $.674^{* *}$ & 1.000 & & & \\
3 & 4.96 & 1.297 & $.596^{* *}$ & $.610^{* *}$ & 1.000 & & \\
4 & 3.77 & 1.760 & .018 & .040 & $.142^{* *}$ & 1.000 & \\
5 & 4.90 & 1.399 & $.393^{* *}$ & $.406^{* *}$ & $.442^{* *}$ & $.116^{* *}$ & 1.000 \\
Age & 2.50 & 1.118 & .006 & .028 & .034 & .004 & -.048 \\
Gender & .50 & .500 & .002 & -.013 & -.033 & -.011 & .006 \\
Income & 4.60 & 1.975 & .007 & -.022 & -.016 & -.007 & .010 \\
Education & 3.40 & .939 & $.098^{* *}$ & $.066^{*}$ & .047 & $.063^{*}$ & $.060^{*}$ \\
\hline
\end{tabular}

NOTE: S.D. $=$ Standard Deviation,

$1=$ We have a reliable government; $2=$ We have a legal government; $3=$ Our government has strong capability; $4=$ I can influence the government's decision making; $5=$ The process for constitution and establishing policies are complicated in China.

$* * * p<0.01 * * p<0.05 * p<0.1$

The second efficacy item, simplicity (i.e., "The process for constitution and establishing policies are complicated in China") had a coefficient of -.060 from the 90 percent trust rate. This means that the Chinese government's policy decision process was considered more complex as the respondent's level of education rose.

In general, when I excluded the nonsignificant items, I found a high level of political trust: The more educated the respondent, the higher he or she assessed government trust and legality. Also, reactivity toward government policy was low and complexity of the policy decision process more highly assessed according to education level.

This is a partial result, because acceptable statistical values resulted for only two of the three items that composed political efficacy according to Paige's analysis. However, those who had a high level of education also had a dependent political orientation, as can be seen in a traditional government system, because they had a high amount of trust in the government and a low sense of political efficacy.

The other demographic variables failed to show significant results in the correlation analysis. Thus, I examined whether there were differences on each trust and efficacy item by demographic subgroup.

As can be seen in Table 5, there were no differences among subgroups regarding the 
three trust items and one of the efficacy items (reactivity). However, simplicity (i.e., "The process for constitution and establishing policies are complicated in China") varied by subgroup as indicated by an $\mathrm{F}$ value of 3.722 from the 95 percent acceptability rate. Also, when I compared this with the change transition of mean scores, I found that the mean scores generally declined. I took this to mean that as the age of the respondent increased, the policy decision process was understood to be more complex.

〈Table 5〉 The Result of Anova Analysis on Age, Income, Education

\begin{tabular}{cccccccccccc}
\hline & \multicolumn{2}{c}{1} & \multicolumn{2}{c}{2} & \multicolumn{3}{c}{3} & \multicolumn{2}{c}{4} & \multicolumn{2}{c}{5} \\
& df & $\mathrm{F}$ & $\mathrm{df}$ & $\mathrm{F}$ & $\mathrm{df}$ & $\mathrm{F}$ & $\mathrm{df}$ & $\mathrm{F}$ & $\mathrm{df}$ & $\mathrm{F}$ \\
\hline Age & 3 & .325 & 3 & .933 & 3 & 1.268 & 3 & 1.205 & 3 & $3.722^{* *}$ \\
Income & 9 & $2.751^{* *}$ & 9 & 1.564 & 9 & 1.603 & 9 & $2.369^{* *}$ & 9 & .861 \\
Education & 5 & $3.177^{* *}$ & 5 & 1.755 & 5 & .808 & 5 & $1.882^{*}$ & 5 & 1.715 \\
\hline
\end{tabular}

NOTE: 1 = We have a reliable government; $2=$ We have a legal government; $3=$ Our government has strong capability; 4 = I can influence the government's decision making; $5=$ The process for constitution and establishing policies are complicated in China. $* * * p<0.01 * * p<0.05 * p<0.1$

According to Table 5, the reliability of the government varies by average monthly household income, as indicated by an $\mathrm{F}$ value of 2.751 from the 95 percent acceptability rate. In addition, reactivity varied by subgroup as indicated by an $\mathrm{F}$ value of 2.369 from the 95 percent acceptability rate. Comparing each subgroup's transition of mean scores for these two items, I found a rising trend for trust. There was also a big difference between the lowest and highest income classes (3.51 and 4.46, respectively) for reactivity. However, the classes in the middle showed zigzag trends. Therefore, I conclude that the sample has more trust in the government as average monthly household income increases, but no fixed trend was evident regarding influence on government policies (i.e., reactivity).

Table 5 also shows that there were differences by education among subgroups on reliability and reactivity. Each of the six education groups showed an F value of 3.1777 from the 95 percent trust rate for government trust and an $\mathrm{F}$ value of 1.882 from the 90 percent trust rate for reactivity. The rising trend in mean score for political trust showed that respondents had more trust in the government the higher their education level. Moreover, because there was a declining trend in mean scores for reactivity, I conclude that respondents with high levels of education believe they cannot influence government policies. This is similar to the results of the general trends and the correlation analysis. 
〈Table 6〉 The Result of T-Test Analysis on Gender

\begin{tabular}{ccccccccccc}
\hline & \multicolumn{2}{c}{1} & \multicolumn{2}{c}{2} & \multicolumn{2}{c}{3} & \multicolumn{2}{c}{4} & \multicolumn{2}{c}{5} \\
\hline Gender & Mean & S.D. & Mean & S.D. & Mean & S.D. & Mean & S.D. & Mean & S.D. \\
Male & 5.01 & 1.291 & 5.01 & 1.302 & 4.91 & 1.347 & 3.75 & 1.759 & 4.91 & 1.403 \\
Female & 5.00 & 1.233 & 5.05 & 1.261 & 5.00 & 1.244 & 3.79 & 1.763 & 4.89 & 1.396 \\
F & 2.542 & \multicolumn{2}{c}{.529} & $8.158^{*}$ & \multicolumn{2}{c}{.035} & \multicolumn{2}{c}{.072} \\
\hline
\end{tabular}

NOTE: S.D. $=$ Standard Deviation,

$1=$ We have a reliable government; $2=$ We have a legal government; $3=$ Our government has strong capability; 4 = I can influence the government's decision making; $5=$ The process for constitution and establishing policies are complicated in China.

$* * * p<0.01 * * p<0.05 * p<0.1$

Table 6 shows the influence of gender on each trust and efficacy item. Men and women did not seem to vary statistically other than on attitude toward government capability. There was an $\mathrm{F}$ value of 8.158 from the 90 percent trust rate for government capability. Also, when compared with the transition of means scores, women assessed the capability of the government to be higher than men did.

According to the preliminary results, relationships among demographic variables (i.e., age, gender, income, and education), political trust, and political efficacy varied for each variable. No variable other than education showed a fixed trend for the trust and efficacy items in Paige's matrix. That is, of the demographic variables, only education was able to explain the types of political orientation in these data.

According to the results of the correlation analysis and the analyses of variance, level of education was significant in both the reliability and reactivity items. The higher their education level, the more respondents considered their government reliable but, in contrast, also believed that they had less ability to influence governmental policies. ${ }^{23)}$ As mentioned previously, this is characteristic of subordinate political orientation, which is found in traditional political systems. This is similar to Chinese college students who believe political truth and authority exist separately, a political orientation known as pragmatism. ${ }^{24)}$ Although respondents with high levels of education trust the Chinese government for high economic growth, respondents reacted very realistically regarding their influence on the policy decision process through the 1989 movement.

According to the results of the correlation analysis, age did not show a fixed correlation with trust and efficacy items. However, the analyses of variance showed that

23) This result shows the distinction from previous research. In particular, Shi (1999) shows the education level is proportioned to internal and external efficacy, and Chen (2004) claims that the education level is inversely proportional to political trust. The reason for these different results could be the divergence of areas, the period of research and specific research design.

24) Chan (1999), pp. 382-83. 
age did show a difference by subgroup for simplicity. Respondents assessed the government's policy process to be more complex as their age increased. The categorization of political orientation was not possible, however, because correlations for this variable did not vary by subgroup for any of the trust items.

The income variable did not show any difference among subgroups, but it did show a fixed correlation with reliability. Hence, although this variable was also impossible to categorize, I conclude that there is more political reliability the higher the income.

The gender variable did not show any difference among subgroups, but the results of the correlation analysis did show a fixed correlation with capability: Women tended to assess the Chinese government's capability to be higher than men did. However, this was also impossible to categorize.

\section{Type of Political Orientation According to Region}

This section categorizes type of political orientation according to region. To determine the types, I performed a Duncan post-inspection on the attitudes toward each trust and efficacy item of residents in each region.

For each trust item, residents showed differences from the 99 percent statistical trust rate in the order of Beijing, Guangzhou, and Shanghai. Beijing residents gave the highest assessment regarding reliability, legality, and capability, followed by residents in Guangzhou and Shanghai. Thus, Beijing residents trusted the government the most, followed by those in Guangzhou and Shanghai (see Table 7).

〈Table 7〉 Political Trust by Region

\begin{tabular}{|c|c|c|c|c|c|}
\hline & Beijing & Shanghai & Guangzhou & Total & $\mathrm{F}$ \\
\hline Political Trust (alpha $=0.8342$ ) & $5.44(1.03) \mathrm{a}$ & $4.63(0.99) \mathrm{c}$ & $4.92(1.14) b$ & $5.00(1.11)$ & 75.469 *** \\
\hline Reliability & $5.46(1.19) \mathrm{a}$ & $4.68(1.08) \mathrm{c}$ & 4.87(1.37) b & $5.00(1.26)$ & $56.267^{* * *}$ \\
\hline Legality & $5.50(1.21) \mathrm{a}$ & $4.63(1.11) \mathrm{c}$ & 4.96(1.36) b & $5.03(1.28)$ & $63.130 * * *$ \\
\hline Capability & $5.37(1.24) \mathrm{a}$ & $4.58(1.20) \mathrm{c}$ & 4.92(1.33) b & 4.97(1.30) & $48.627^{* * *}$ \\
\hline
\end{tabular}

For each efficacy item, residents showed differences from a 99 percent statistical trust rate in the order of Shanghai, Guangzhou, and Beijing. Shanghai residents gave the highest assessment regarding reactivity and simplicity, followed by residents in Guangzhou and Beijing. Thus, Shanghai residents scored highest, followed by those in Guangzhou and Beijing, in terms of political efficacy (see Table 8). In addition, these 
three areas seem to have, in general, subordinate-political orientation showed in the traditional political system as shown in Table 7 and 8 . This is because the numerical data of trust is higher than that of efficacy when political trust and efficacy are compared.

〈Table 8〉 Political Efficacy by Region

\begin{tabular}{|c|c|c|c|c|c|}
\hline & Beijing & Shanghai & Guangzhou & Total & $\mathrm{F}$ \\
\hline Reactivity & $3.23(1.85) \mathrm{c}$ & $4.19(1.48) \quad \mathrm{a}$ & $3.87(1.79) \quad b$ & $3.77(1.76)$ & $40.586^{* * *}$ \\
\hline Simplicity & $2.74(1.32) \mathrm{c}$ & $3.44(1.33) \mathrm{a}$ & $3.11(1.46) \quad b$ & $3.10(1.40)$ & $33.260 * * *$ \\
\hline
\end{tabular}

*** $\mathrm{p}<.001, \quad \mathrm{a}, \mathrm{b}, \mathrm{c}$ : The results of Duncan Multiple Comparison. $\quad$ Alpha is Confidence Coefficient

I next arranged these results according to the matrix in Figure 1. As shown in Figure 2 , Beijing residents tended to have subordinate political orientations, which appear in traditional political systems. In contrast, Shanghai residents tended to have dissident political orientations, which appear in unstable political systems. Guangzhou residents were somewhere in the middle. ${ }^{25)}$

〈Figure 2〉 The Patterns of Political Orientation of Beijing, Shanghai, and Guangzhou Residents

\begin{tabular}{|c|c|c|}
\hline & & \\
\hline & High & Low \\
\hline & Allegiant & Dissident \\
\hline High & & Shanghai \\
\hline & Democratic & Unstable \\
\hline Efficacy & $\mathrm{Gt}$ & rou \\
\hline & Subordinate & Alienated \\
\hline Low & Beijing & \\
\hline & Traditional & Totalitarian \\
\hline
\end{tabular}

What prompted these results? The main theme of this research is to investigate the existence of political difference and type between these three areas. In order to provide the clue for related research hereafter, however, the two factors can be considered as follows. ${ }^{26)}$ The first is related to the political orientations of Beijing and Shanghai. As mentioned previously, Beijing residents showed traditional political orientations, and

25) This classification is based on the relative comparison of these three areas.

26) In this sense, this research focuses upon 'discovery' of the new fact rather than 'analysis' of that fact. 
Shanghai residents showed unstable political orientations. This clear difference is perhaps the result of differences in cultural background. Beijing was a traditional agricultural society until the 19th century, whereas Shanghai had more developed trade and industry through engaging in both voluntary and involuntary interchanges with the West after the 19th century. Therefore, Beijing has had a relatively traditional and conservative culture, whereas Shanghai has had a more Westernized and liberal culture. ${ }^{27)}$

Even developments after the establishment of the People's Republic of China were different in these two cities. As China's capital city, Beijing enjoyed periods of planned and market economies with complete support from the government. Hence, trust in the political system can be presumed to be very high. However, the political and cultural control levied by the government was harsher than in any other city. One example is the Tiananmen incident in 1989. The citizens' political protests were completely suppressed by the military. This incident caused the citizens to fear an actual political wall and the formation of a non-intervening atmosphere. ${ }^{28)}$ Thus, I conclude that citizens in Beijing have formed a traditional, Confucian political orientation of giving the required trust to the government, while avoiding intervening.

In contrast, Shanghai experienced definite changes over the years. In terms of national developmental strategy, Mao implemented a regional balanced development policy that specifically supported inland areas. During this period, Shanghai was neglected. After 1980, the country experienced rapid economic growth and became active when Deng Xiaoping issued the decentralization reformation. The development of the area was hastened when leaders such as Jiang Zemin who were based in Shanghai advanced to high-ranking positions in the country. ${ }^{29)}$ As a result, Shanghai's history after the establishment of the People's Republic of China and Deng's reign contrasts sharply with that of Beijing. These events did not seem to heighten trust in the government among Shanghai residents. This is also related to traditional regional decentralization.

The high political efficacy of Shanghai residents may be closely related to recent events. Since 1989, political leaders based in this region have stood as the main leaders of the nation. Therefore, residents in this area relative to other areas may think that they have a certain amount of influence on the government. The fact that Shanghai has

27) Hairen Zhang, "Huabei he huadong wenhua zhi genyuan" (The Root of Huabei and Huadong Region), Zhongguo renwen kexue (Chinese Liberal Science) (Beijing, 2000) 25, pp. 32-38.

28) Richard W. Wilson, "Change and Continuity in Chinese Cultural Identity: The Filial Ideal and the Transformation of an Ethic," in Lowell Dittmer and Samuel S. Kim (eds.), China's Quest for National Identity (Ithaca, NY, and London: Cornell University Press, 1993), pp. 122-23.

29) Alan P. L. Liu, "Mini-Nationalism in Post-Mao China," Problem of Post-Communism 49-2 (March/April 2002), pp. 46-48. 
not experienced a political ordeal such as the Tiananmen incident could also be a reason for its differences from Beijing. ${ }^{30}$

The second factor to consider when analyzing these results is why the political orientations of Guangzhou residents are somewhere in the middle of those of Beijing and Shanghai residents. Specifically, Shanghai and Guangzhou share similar histories, socioeconomic structures, and long-term interest in reforms. These cities were once considered to have the same type of political culture. ${ }^{31)}$ In spite of this, they have different political orientations. Specifically, Guangzhou residents tend to be higher on political trust and lower on political efficacy. This can be analyzed from two perspectives. First, the history, geography, and economy of Guangzhou have been greatly influenced by Hong Kong. Therefore, there is a high chance of Guangzhou having a similar political orientation as Hong Kong. Hong Kong's political culture, namely a sense of powerlessness, a desire for stability, and adaptation, influenced Guangzhou. This may be why Guangzhou residents have more political trust than Shanghai residents but less than Beijing residents. Moreover, Hong Kong's self-interested, materialistic, and non-ideological political culture also has influenced Guangzhou. This may be why Guangzhou residents have less political efficacy than Shanghai residents. ${ }^{32}$

Second, in terms of national developmental strategy, although there was an aspect of "receiving unilateral benefits" from Deng during the 1980s, Shanghai also was "making its own benefits" through political leaders whose bases were in Shanghai during the 1990s. ${ }^{33)}$ Therefore, in terms of political trust (especially in light of the year [2005] the survey was conducted, when Jiang Zemin relinquished authority to Hu Jinato), Guangzhou is higher in political efficacy than Shanghai.

30) Such high political efficacy among Shanghai residents may be represented by recent resistance to the central government's retrenchment policy. In the event, the city's mayor, Chen Liangyu, stood against other major leaders of the center. See Xin Qiu, "Wenzong xiang Chen Liangyu fa zuihou tongdie" (Premier Wen sends the latest notification to Chen Liangyu), Yazhou shibao (Asian Times), June 4, 2005.

31) Liu (1996), p. 255.

32) For more on Hong Kong's political culture, see Lam Wai-Man, Understanding the Political Culture of Hong Kong (Armonk, NY: Sharpe, 2004), pp. 227-30.

33) Fengchun Wang, "Guangdong yu shanghai fazhan moshi bijiao" (A comparative analysis of the developmental model of Guangdong and Shanghai), Guojia zhanlue (State Strategy) (Beijing, 2002) 12, pp. 23-25. 


\section{Conclusion}

This study was designed to examine whether political characteristics vary by region in China. For this study, 500 people in Beijing, Shanghai, and Guangzhou were surveyed in June 2005. The study used Paige's model of political orientation to investigate differences in political orientation by region.

Of the demographic variables studied (i.e., education, age, gender, and income), only education was statistically related to political orientation. The more educated are the residents in region, the more did their political orientation tend to be subordinate or submissive type that can be seen in traditional political systems. Other variables were impossible to categorize as political types and showed only major trends.

The relationship between regional variables and political orientation showed valid results. Beijing, Shanghai, and Guangzhou residents varied in political trust, political efficacy and subgroups of political orientation. Beijing residents tended to have subordinate political orientations, as can often be seen in traditional political systems. However, Shanghai residents tended to have dissident political orientations, as can be seen in unstable political systems. Guangzhou residents showed political orientations somewhere in the middle. Thus, I reached a positive result for the hypothesis of whether political characteristics vary by region in China. Moreover, I was able to identify the characteristics of political orientation in each region.

This study has the following implications. First, it reveals a fixed positive political basis regarding differences among regions in China. This corresponds to recent scientific trends in regional understanding and investigation in China. Second, transitions in political orientation can be better understood if studies are performed periodically at fixed intervals, as some scholars have already attempted to do.

However, this study also has some limitations. First, these results must be verified through more surveys of more regions. Second, the study was successful in verifying the hypothesis but lacked a causal analysis. Thus, deeper complementary research on why residents in Beijing, Shanghai, and Guangzhou have such political orientations is needed. Finally, the study should be expanded to investigate and compare results, existing democratic theories, and political orientations in other developing countries. 


\section{REFERENCES}

Beijing Statistical Bureau. 2005. "2004nian beijing guomin jingji he shehui fazhan tongji gongbao" (Beijing economic and social development statistics bulletin, 2004). http://www.stats.gov.cn/tjgb/ndtjgb/dfndtjgb/t20050228_402231969.htm.

Chan, Chepo. "The Political Pragmatism of Chinese University Students: 10 Years after the 1989 Movement." Journal of Contemporary China 8-22 (November 1999).

Chen, Jie, Zhong Yang and Jan William Hillard. "The Level and Sources of Popular Support for China's Current Political Regime." Communist and Post Communist Studies 30-1 (March 1997).

Chen, Jie. Popular Political Support in Urban China. Stanford: Stanford University, 2004.

- "Sociopolitical Attitudes of the Masses and Leaders in the Chinese Village: Attitude Congruence and Constraint." Journal of Contemporary China 14-44 (August 2005).

Child, John, and Sally Stewart. "Regional Differences in China and Their Implications for Sino-Foreign Joint Ventures." Journal of General Management 23-2 (Winter 1997).

Chung, Jae Ho. Central Control and Local Discretion in China. Oxford: Oxford University Press, 2000.

Dowd, Daniel V., Allen Carlson and Mingming Shen. "The Prospects for Democratization in China: Evidence from the 1995 Beijing Area Study." Journal of Contemporary China 8-22 (November 1999).

Guangzhou Statistical Bureau. Guangzhou tongji nianjian 2004 (Guangzhou statistical yearbook, 2004). Beijing: China Statistical Press, 2005.

Hendrischke, Hans, and Feng Chongyi. The Political Economy of China's Provinces. London: Routledge, 1999.

Hsin-Chi, Kunan, and Lau Siu-Kai. "Traditional Orientation and Political Participation in Three Chinese Societies.” Journal of Contemporary China 11-31 (May 2002).

Jennings, Kent. "Political Participation in the Chinese Countryside." American Political Science Review 91-4 (December 1997).

Keating, Michael. "Rethinking the Region: Culture, Institutions and Economic Development in Catalonia and Galicia.” European Urban and Regional Studies 8-3 (July 2001). 
Lam, Wai-Man. Understanding the Political Culture of Hong Kong. Armonk, NY: Sharpe, 2004.

Liu, Alan P. L. Mass Politics in the People's Republic: State and Society in Contemporary China. Boulder, CO: Westview Press, 1996.

. "Provincial Identities and Political Cultures: Modernism, Traditionalism, Parochialism, and Separatism," in Shiping Hua, ed. Chinese Political Culture 19892000. Armonk, NY: Sharp, 2001.

"Mini-Nationalism in Post-Mao China." Problem of Post-Communism 49-2 (March/April 2002).

Manion, Melanie. "The Electoral Connection in the Chinese Countryside." American Political Science Review 90-4 (December 1996).

Nathan, Andrew J., and Tianjian Shi. "Cultural Requisites for Democracy in China: Finding from a Survey.” Daedalus 122 (Spring 1992).

. "Left and Right with Chinese Characteristics, Issues and Alignments in Deng Xiaoping's China." World Politics 48-4 (July 1996).

Paige, Jeffery M. "Political Orientation and Riot Participation." American Sociological Review 36-5 (October 1971).

Paasi, Anssi. "Region and Place: Regional Identity in Question." Progress in Human Geography 27-4 (August 2003).

Qiu, Xin. "Wenzong xiang ChenLiangyu fa zuihou tongdie." (Premier Wen sends the latest notification to Chen Liangyu). Yazhoushibao (Asian Times), June 4, 2005.

Shanghai Statistical Bureau 2005. "2004nian shanghai guomin jingji he shehui fazhan tongji gongbao" (Shanghai economic and social development statistics bulletin, 2004). http://www.stats.gov.cn/tjgb/ndtjgb/dfndtjgb/t20050126_402226082.htm.

Shi, Tianjian. Political Participation in Beijing. Cambridge, MA: Harvard University Press, 1997.

"Mass Political Behavior in Beijing," in Merle Goldman and Roderick MacFarquhar, eds. The Paradox of China's Post-Mao Reforms. Cambridge, London: Harvard University Press, 1999.

Skinner, G. W. The City in Late Imperial China. Stanford, CA: Stanford University, 1977.

State Statistical Bureau, General Statistics Division of National Economy. Xinzhongguo wushiwu nian tongji ziliao huibian 1949-2004 (China compendium of statistics 1949-2004). Beijing: China Statistical Press, 2005. 
State Statistical Bureau of the People's Republic of China. 2004. "Shewai diaocha guanli banfa" (Procedure for outside investigations management).

State Statistical Bureau, Politics and Law Division. 2004. "Shewai diaocha guanli banfa" (State Statistical Bureau press interview).

http://www.stats.gov.cn/tjgl/sxdcglgg/zywj/t20041118_402209070.htm.

. 2004. "Shewai diaocha guanli banfa" (Foreign investigation management approach). http://www.stats.gov.cn/tjgl/sxdcglgg/zywj/t20041118_402209070.htm.

. 2004. "Qude shewai diaocha xukezheng jigou mingdan (di yi pi)" (The list of agencies to obtain 'A Permit for Outside Investigation' [1]). http://www.stats.gov.cn/tjgl/swdcglgg/spgg/t20041118_402209054.htm.

. 2005. "Qude shewai diaocha xukezheng jigou mingdan (di er pi)" (The list of agencies to obtain 'A Permit for Outside Investigation' [2]).

http://www.stats.gov.cn/tjgl/swdcglgg/spgg/t20050414_402242828.htm.

. 2005. "Qude shewai diaocha xukezheng jigou mingdan (di san pi)" (The list of agencies to obtain 'A Permit for Outside Investigation' [3]).

http://www.stats.gov.cn/tjgl/swdcglgg/spgg/t20050414_402264266.htm.

Wang, Fengchun. "Guangdong yu shanghai fazhan moshi bijiao" (A comparative analysis of the developmental model of Guangdong and Shanghai). Guojia zhanlue (State Strategy) (Beijing) 12 (2002).

Wang, Yanlai, Nicholas Rees and Bernadette Anreosso-O'Callaghan. "Economic Change and Political Development in China: Finding from a Public Opinion Survey." Journal of Contemporary China 13-39 (May 2004).

Wilson, Richard W. "Change and Continuity in Chinese Cultural Identity: The Filial Ideal and the Transformation of an Ethic," in Lowell Dittmer and Samuel S. Kim, eds. China's Quest for National Identity. Ithaca, NY, and London: Cornell University Press, 1993.

Zhang, Hairen. "Huabei he huadong wenhua zhi genyuan" (The root of Huabei and Huadong region). Zhongguo renwen kexue (Chinese Liberal Science) (Beijing) 25 (2000). 